\title{
Temporal arteritis presenting with scalp ulceration
}

\author{
C Monteiro, * B Fernandes, J Reis, O Tellechea, J Freitas, A Figueiredo \\ Department of Dermatology, University Hospital, Praceta Prof Mota Pinto, 3000-075 Coimbra, Portugal. *Corresponding author, Serviço de \\ Dermatologia, Hospitais da Universidade de Coimbra, Praceta Prof Mota Pinto, 3000-075 Coimbra, Portugal, tel. +351239400420 ; \\ fax+351 239400 490; E-mail: c.monteiro@netc.pt
}

\begin{abstract}
We report the case of a 75-year-old-woman who presented with bilateral scalp ulcerations and blindness, accompanied by severe headache and scalp tenderness, due to bilateral temporal arteritis without systemic involvement. A biopsy taken from the border of an ulceration showed evidence of giant cell arteritis. She was treated with oral prednisone, $60 \mathrm{mg}$ per day. The ulcerations healed in a few weeks but the vision loss was irreversible.

This case highlights for temporal arteritis the importance of accurate and timely diagnosis as well as the need for prompt therapy with systemic steroids in order to avoid major complications, namely loss of vision. It also demonstrates that scalp necrosis and ulcerations are skin signs associated with a poor prognosis.

Key words: temporal arteritis, giant cell arteritis, scalp ulceration, blindness
\end{abstract}

Received: 2 April 2001, accepted 26 March 2002

\section{Introduction}

Temporal arteritis or giant cell arteritis is a systemic granulomatous vasculitis of the medium and large-sized arteries, involving most frequently the temporal artery. It is a rare disease that affects mainly elderly persons, particularly women. It presents classically with headache, fever, high ESR and anaemia. Other manifestations can include fatigue, lassitude, malaise, weight loss, depression, sweating and arthralgia. Claudication, strokes, myocardial infarction, purpuric eruptions and gangrene of the legs may also occur as a result of systemic vasculitis. Polymyalgia rheumatica syndrome is a frequently associated disease, characterized by stiffness and aching pains in the muscles of the neck, shoulders, pelvic girdle and limbs. ${ }^{1,2}$

We report a case of temporal arteritis in a 75-year-old woman, manifested by bilateral scalp ulcerations and blindness.

\section{Case report}

A 75-year-old woman, presenting extensive tender scalp ulcerations and crusted lesions on both the right and left temporoparietal regions (fig. 1), accompanied by bilateral vision loss, with 4 weeks of evolution, was admitted to our Department of
Dermatology for further investigation and treatment. No other cutaneous or systemic signs or symptoms were noticed.

Four months before she had been admitted to a neurology unit with severe headaches, where laboratory studies and brain CT disclosed only an elevated erythrocyte sedimentation rate (ESR) $(61 \mathrm{~mm} / \mathrm{h})$. At that time, a diagnosis of temporal arteritis was ruled out based on an unresponsive 2-week therapeutical trial with systemic steroids. Analgesics were given for the headache.

Laboratory studies done in our department, including haematologic and biochemical blood parameters, urine analysis, rheumatoid factors, circulating immune complexes, C3 and C4 levels, proteinogram and immunoelectrophoresis, antinuclear antibodies, cardiolipin antibodies, VDRL, chest X-ray, ECG and brain $\mathrm{CT}$, were all negative or in the normal range, except $\mathrm{C}$ reactive protein: $4.5 \mathrm{mg} / \mathrm{dL}$ (normal range: $0.0-1.0$ ). The ESR was $30 \mathrm{~mm} / \mathrm{h}$ (normal range: $0-35$ ).

A 2-cm length biopsy of the left temporal superficial artery showed a lymphohistiocytic infiltrate closely related to the internal elastic lamina, inducing its focal fragmentation, and intimal proliferation with myxomatoid changes (fig. 2). A punch biopsy from the border of an ulceration disclosed multinucleated giant cells in the wall of a medium-sized muscular vessel (fig. 3). 


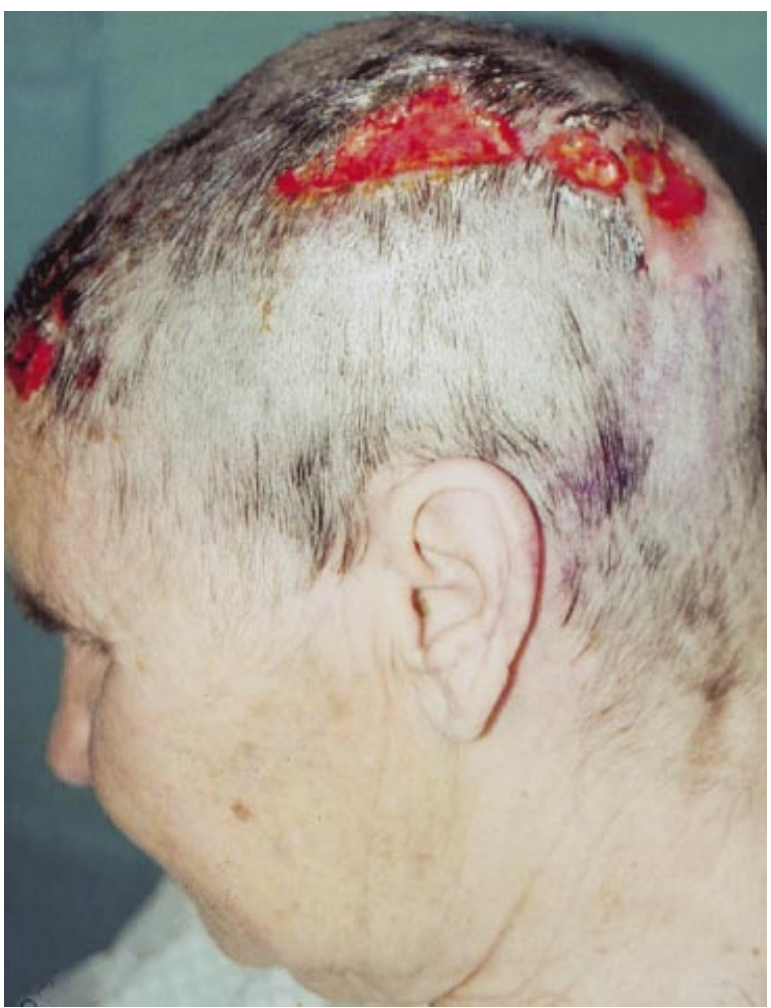

fig. 1 Extensive scalp ulcerations of the left temporoparietal region. The right side showed less extensive ulcerations.

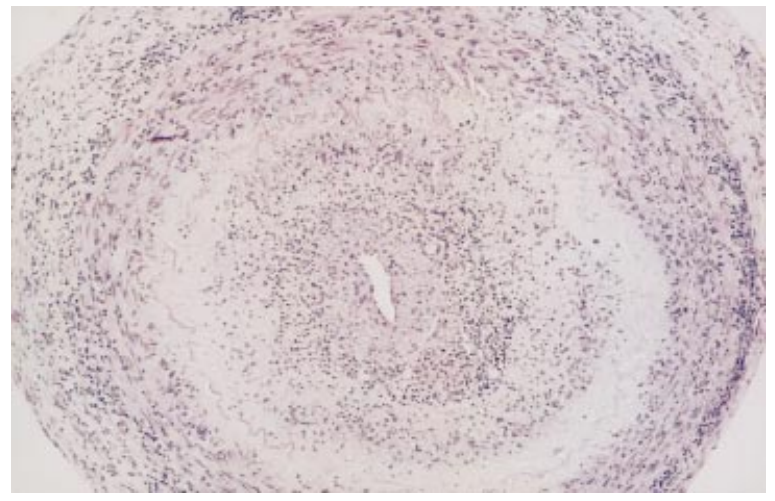

fig. 2 Biopsy of the left superficial temporal artery, showing a narrowed lumen with subintimal proliferation and focal fragmentation of the internal elastic lamina. There is a lymphohistiocytic infiltrate within the vessel wall. No multinucleated giant cells are seen. $(\mathrm{H} \& \mathrm{E} ; \times 100)$.

The woman was immediately treated with oral prednisone (started before the biopsies were taken) at a dosage of $60 \mathrm{mg} /$ daily $(1 \mathrm{mg} / \mathrm{kg})$ for approximately 3 weeks, followed by gradual tapering to a maintenance dose of $10 \mathrm{mg}$ per day, continued for almost 1 year. The headache and scalp tenderness subsided within 2 weeks, ESR fell to $1 \mathrm{~mm} / \mathrm{h}$ in 2 weeks, ulcerations healed gradually in 4 weeks with scar formation (fig. 4), however, the woman's loss of vision was irreversible.

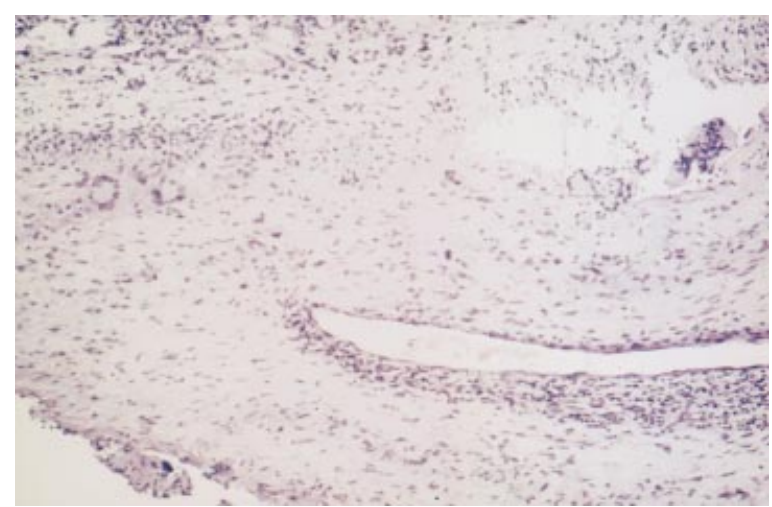

fig. 3 Biopsy taken from the border of an ulceration, disclosing multinucleated giant cells in the wall of a medium sized artery. (H\&E; $\times 100)$.

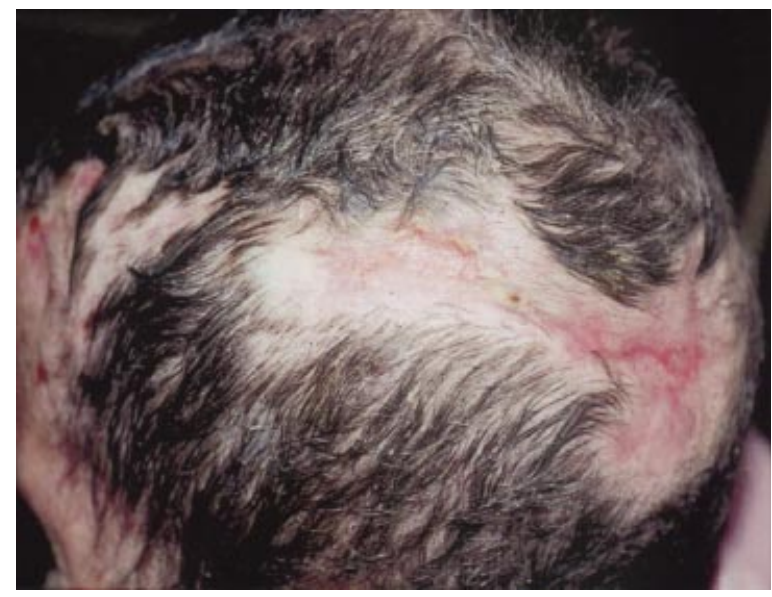

fig. 4 Left side of the scalp, after 4 weeks of therapy.

\section{Discussion}

Temporal arteritis is a regional variant of giant cell arteritis that affects the temporal artery, sometimes without accompanying clinical symptoms of systemic involvement, ${ }^{3}$ as in our case. Headache, unilateral or bilateral, is the main symptom, and may be associated with tenderness over a prominent, tortuous and thickened superficial temporal artery. Pulsation may be reduced or absent. Jaw and tongue claudication are frequent and are due to ischaemia of the muscles of mastication. Glossitis and tongue necrosis may also occur.1,2,4,5 A dreadful complication of temporal arteritis, particularly in untreated patients, is blindness, due to ischaemic optic neuritis. ${ }^{3}$ Although rare, scalp necrosis and ulceration are the most common dermatologic findings. They may be unilateral or bilateral, sometimes involving large areas of the scalp.4,5 They may extend deeply, even into the bone. ${ }^{6}$

The typical laboratory finding in giant cell arteritis is a moderate to marked elevation of ESR, but normal ESR is not rare (2-8\% of cases), even in the acute phase of the disease. 4 Additionally, normochromic or slightly hypochromic anaemia 
and sometimes polymorphonuclear leukocytosis may be present. ${ }^{1,2}$

The diagnosis of temporal arteritis is often made clinically based on the classic symptom complex of headache, fever, anaemia and high ESR. Because most of the systemic manifestations of temporal arteritis are non-specific and common to other diseases, and because long-term high doses of systemic steroids are the standard treatment, a definitive diagnosis should be based on a biopsy of the temporal artery. Five to $10 \%$ of cases however, present false negative temporal artery biopsy, with potentially disastrous consequences if appropriate therapy is delayed. ${ }^{7}$

Differential diagnosis should be made with other vasculitides, with certain bullous diseases, particularly BrunstingPerry-type cicatricial pemphigoid, and with herpes zoster infection. Although the disease can sometimes be identified clinically, definitive diagnosis of temporal arteritis rests on the demonstration of giant cell arteritis in bioptic specimens from the superficial temporal artery.

Although dermatologists rarely diagnose cases of temporal arteritis, because skin signs are rare and late, we must all be aware of its cutaneous manifestations because, as illustrated by the present case, they may be the main or only signs that arise suspicion, and they are associated with an increased risk of vision loss and other catastrophic sequelae. ${ }^{3-5}$ This diagnosis should be taken into consideration early and confirmed by biopsy of the temporal artery, however, therapy should not be delayed until a biopsy is performed, since early aggressive therapy reduces dramatically morbidity, namely vision loss.3,4,7 The present case is an example in which accurate and timely diagnosis by diagnostic temporal artery biopsy (obtained during the phase of headaches) along with the appropriate therapy could have avoided loss of vision. Positive giant cell arteritis biopsies can be obtained, even after weeks to months of glucocorticoid therapy.7 In our case, a biopsy-proven temporal arteritis was obtained after 1 week of therapy. Because involvement of the vessel may be segmental, serial sections are recommended. ${ }^{7}$ Our case also shows that the characteristic histological findings may be found in the smaller vessels of the scalp.

Temporal arteritis is extremely sensitive to systemic glucocorticoids. Treatment should begin with prednisone, 40-60 mg per day, followed (as symptoms subside) by gradual tapering to a maintenance dose of 7.5-10 mg per day for 1-2 years, to avoid relapses. ${ }^{2}$

\section{References}

1 Fritsch PO. Giant Cell Arteritis. In: Fitzpatrick TB, Eisen AZ, Wolff K, Freedberg IM, editors. Dermatology in General Medicine, 4th ed. Mc Graw-Hill, New York, 1993: 1651-1658.

2 Ryan TJ. Cutaneous vasculitis. In: Champion RH, Burton JL, Burus DA, Breathnach SM, editors. Rook/Wilkinson/Ebling Text Book of Dermatology, 6th ed. Blackwell Science, Oxford, 1998: 2223-2225.

3 Dudenhoefer EJ, Corblath WT, Schatz MP. Scalp necrosis with giant cell arteritis. Ophthalmology 1998; 105: 1875-1878.

4 Abdullah AN, Keczkes K, Wyatt EH. Skin necrosis in giant cell (temporal) arteritis: report of three cases. B J Dermatol 1989; 120: 843-846.

5 Stoebner PE, Gaspard C et al. Tongue necrosis provoked by ergotamine tartrate and disclosing a giant cell arteritis. Eur J Dermatol 1999; 9: 652-653.

6 Rigon JL, Schmutz JL et al. Nécrose du cuir chevelu et de la voûte crânienne dans la maladie de Horton. Ann Dermatol Venereol 1987; 114: 1561-1565.

7 Albertini JG, Ramsey ML, Marks VJ. Temporal artery biopsy in a dermatologic surgery practice. Dermatol Surg 1999; 25: 501-508.

\section{Visit the EADV website at: www.eadv.org}


Copyright $\odot 2002$ EBSCO Publishing 